\title{
Research on Three-Dimensional Unsteady Turbulent Flow in Multistage Centrifugal Pump and Performance Prediction Based on CFD
}

\author{
Zhi-jian Wang, ${ }^{1}$ Jian-she Zheng, ${ }^{1}$ Lu-lu Li, ${ }^{2}$ and Shuai Luo ${ }^{1}$ \\ ${ }^{1}$ School of Mechatronics Engineering, Shenyang Aerospace University, Shenyang, Liaoning 110136, China \\ ${ }^{2}$ Haicheng Suprasuny Pump Co., Ltd., Haicheng, Liaoning 114216, China
}

Correspondence should be addressed to Zhi-jian Wang; wangzhijian1974@sina.com

Received 24 March 2013; Accepted 15 May 2013

Academic Editor: Zhijun Zhang

Copyright (c) 2013 Zhi-jian Wang et al. This is an open access article distributed under the Creative Commons Attribution License, which permits unrestricted use, distribution, and reproduction in any medium, provided the original work is properly cited.

\begin{abstract}
The three-dimensional flow physical model of any stage of the 20BZ4 multistage centrifugal pump is built which includes inlet region, impeller flow region, guide-vane flow region and exit region. The three-dimensional unsteady turbulent flow numerical model is created based on Navier-Stoke solver and standard $k-\varepsilon$ turbulent equations. The method of multireference frame (MRF) and SIMPLE algorithm are used to simulate the flow in multistage centrifugal pump based on FLUENT software. The distributions of relative velocity, absolute velocity, static pressure, and total pressure in guide vanes and impellers under design condition are analyzed. The simulation results show that the flow in impeller is mostly uniform, without eddy, backflow, and separation flow, and jet-wake phenomenon appears only along individual blades. There is secondary flow at blade end and exit of guide vane. Due to the different blade numbers of guide vane and impeller, the total pressure distribution is asymmetric. This paper also simulates the flow under different working conditions to predict the hydraulic performances of centrifugal pump and external characteristics including flow-lift, flow-shaft power, and flow-efficiency are attained. The simulation results are compared with the experimental results, and because of the mechanical losses and volume loss ignored, there is a little difference between them.
\end{abstract}

\section{Introduction}

Pumps are widely used in many fields and the average electric power consumption is about $20.9 \%$ of the total consumption every year in China [1]. Because of the low level of manufacture and design of pumps, the efficiency of domestic pumps is about $10 \%$ lower than that of the developed countries. Among the pumps, the centrifugal ones are most widely applied, but there are many problems such as low efficiency, operated under off-design conditions, and low cavitations performance. Therefore, it will have very important practical significance to study the internal flow of centrifugal pumps in order to optimize the structure of main parts, improve the hydraulic performance, increase the efficiency and avoid being operated under off-design conditions, and thus reach the goal of increasing efficiency and saving energy.

Due to the complex shape of flow channel, high-speedrotating viscous fluid and the interaction between moving and stationary parts, the flow in centrifugal pumps is a threedimensional, viscid, and unsteady complex flow. It becomes more and more popular to investigate the internal flow of the centrifugal pump based on computational fluid dynamic (CFD) owing to the short design time, low price, being observed directly, and making up the deficiency of traditional design methods. With the rapid development of the computer technology, CFD has been one of the main methods to study the flow in the centrifugal pump. Subsequently, it will be possible to design high-efficiency and energy-saving pumps and create huge social and economic benefits. Si and Dike [2] simulated the whole flow field of sectional multistage pump and the simulation was performed in a multiple reference frame and standard $k-\varepsilon$ turbulence model. Li et al. [3] combined sliding-mesh and moving-mesh methods to simulate internal flow during starting procedure of the single-stage pump. Liu and Wang [4] carried out computer-aided analysis 


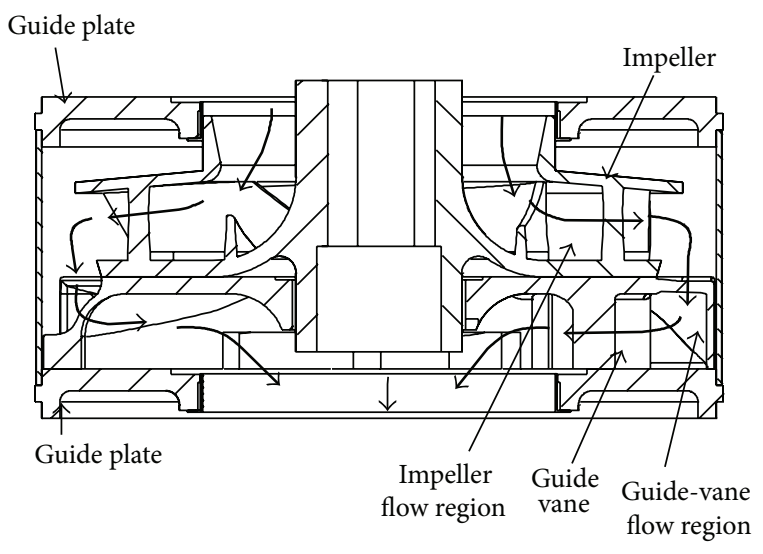

FIGURE 1: Sketch of centrifugal pump.

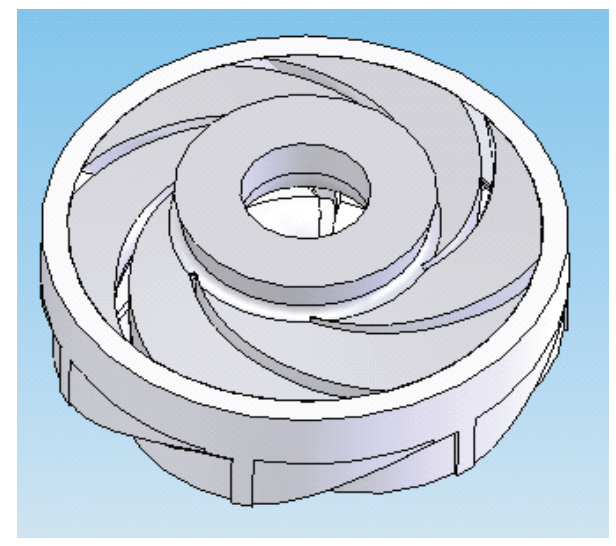

FIGURE 2: Flow region of impeller and guide vane.

on internal flow of stamping and welding centrifugal pump impeller based on CFD using ANSYS CFX and explored the flow mechanism in impeller. Barrio et al. [5] simulated internal flow of centrifugal pump through CFD such that they could predict radical force and torsion suffered by impeller. Jafarzadeh et al. [6] simulated fluid flow of low-specific-speed ratio centrifugal pump. Asuaje et al. [7] performed a 3D-CFD simulation of impeller and volute of a centrifugal pump using CFX code with a specific speed of 32 and found velocity and pressure fields for different flow rates and radial thrust on the pump shaft. Cui et al. [8] investigated the effect of number of splitting blades for long, mid, and short blades using a oneequation turbulent model. Their results show that the bulk flow in the impeller has an important influence on the pump performance. Anagnostopoulos [9] simulated 3D turbulent flow in a radial pump impeller for a constant rotational speed of $1500 \mathrm{rpm}$ based on the solution of the RANS equations. Few of the previous works involved study of 3D modeling within a full domain considering interaction between rotor and stator of a high-speed multistage centrifugal pump using various turbulence models.

This paper uses commercial CFD software FLUENT, standard $k-\varepsilon$ turbulent model and multiply reference frame to perform numerical modeling of the full three-dimensional fluid field for any stage of 20BZ4 multistage centrifugal pump which includes the flow region of import channel, impellers, guide vanes, and exit channel. The pressure and velocity distributions in the pump under design condition are obtained and the numerical performance curves are compared with the experimental ones. It will provide theoretical basis for further optimizing the structures and improving the performances of centrifugal pump.

\section{Numerical Simulation and Method}

2.1. Physical Model. Figure 1 shows the sketch map and flow route in any stage unit of 20BZ4 multi-stage centrifugal pump, which includes guide plates, impellers, and guide vanes. The impeller is made up of front end plate, back end plate and blades. The blades are equipped between front and back end plates, and the number of blades is 5 . The structure of guide vanes is radial and the number of blades is 7. It is made up of positive guide vane and negative guide vane. Positive vane can collect fluid and transform kinetic energy into pressure energy, while negative vane can change flow direction and transmit the fluid into next unit with the required speed and circulation. Guide plate can reduce reflux effectively and make uniform and stable flow velocity of the fluid into the impeller. Fluid flows downward through guide plate, then through the flow runner of impeller into guide vane and finally goes into the next pump unit from guide plate.

The impeller inlet and guide-vane outlet are extended, respectively, in order to ensure stable convergence of internal flow field. The physical model includes inlet region, impeller flow region, guide-vane flow region, and exit region. Figure 2 shows the flow region model of impeller and guide-vane. Structured grids are used in inlet region and exit region because of the cylindrical shape and the numbers of grids are 71607 and 69564, respectively. Unstructured grids are used to mesh impeller and guide-vane flow regions and the numbers of grids are 187561 and 133108, respectively. Figures 3 and 4 show the grids of impeller flow region and guide-vane flow region, respectively.

2.2. Governing Equations and Turbulence Model. The internal flow of centrifugal pump is a three-dimensional, viscous, and unsteady turbulent flow and flow law follows NavierStokes equation. Because the heat exchange is very little in centrifugal pump, energy conservation equation is not considered, and only mass conservation equation and momentum conservation equation need to be solved.

Mass conservation equation is as follows:

$$
\frac{\partial \rho}{\partial t}+\frac{\partial}{\partial x_{i}}\left(\rho u_{i}\right)=0
$$

Momentum conservation equation is as follows:

$$
\frac{\partial}{\partial t}\left(\rho u_{i}\right)+\frac{\partial}{\partial x_{j}}\left(\rho u_{i} u_{j}\right)=-\frac{\partial p}{\partial x_{i}}+\frac{\partial}{\partial x_{j}}\left[\mu \frac{\partial u_{i}}{\partial x_{j}}-\rho \overline{u_{i}^{\prime} u_{j}^{\prime}}\right]+S_{i},
$$

where $\rho$ is fluid density, $u$ is velocity, $p$ is pressure, $t$ is time, $\mu$ is 


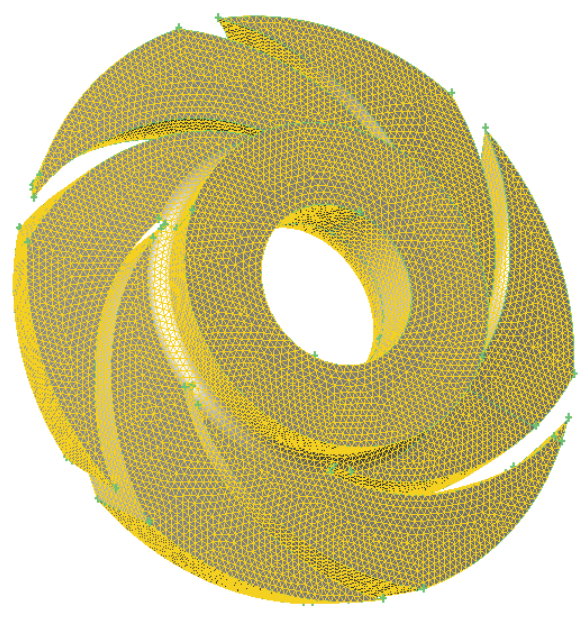

Figure 3: Grids of impeller flow region.

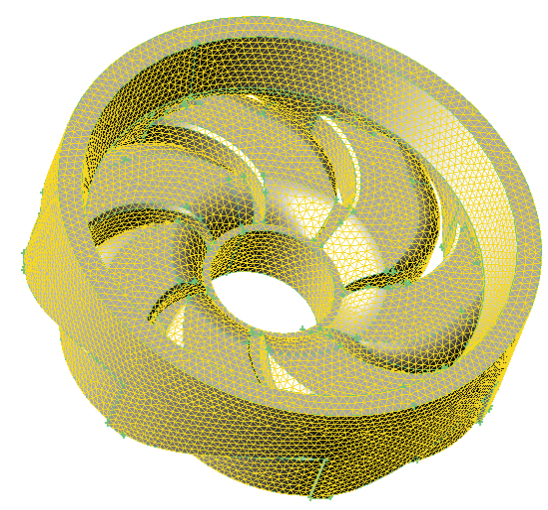

FIGURE 4: Grids of guide-vane flow region.

dynamic viscosity, $S$ is source item, and $\rho \overline{u_{i}^{\prime} u_{j}^{\prime}}$ is the Reynolds stress. $x_{i}$ and $x_{j}$ are the coordinates of $x, y$, and $z$, and $x_{i} \neq x_{j}$.

Standard $k-\varepsilon$ turbulence model is used. Turbulence kinetic energy $k$ equation is as follows:

$$
\frac{\partial(\rho k)}{\partial t}+\frac{\partial\left(\rho k u_{i}\right)}{\partial x_{i}}=\frac{\partial}{\partial x_{j}}\left[\left(\mu+\frac{\mu_{t}}{\sigma_{k}}\right) \frac{\partial k}{\partial x_{j}}\right]+G_{k}-\rho \varepsilon .
$$

Dissipation rate $\varepsilon$ equation is as follows:

$$
\begin{aligned}
\frac{\partial(\rho \varepsilon)}{\partial t}+\frac{\partial\left(\rho \varepsilon u_{i}\right)}{\partial x_{i}}= & \frac{\partial}{\partial x_{j}}\left[\left(\mu+\frac{\mu_{t}}{\sigma_{s}}\right) \frac{\partial \varepsilon}{\partial x_{j}}\right] \\
& +\frac{C_{1 \varepsilon} \varepsilon}{k} G_{k}-C_{2 \varepsilon} \rho \frac{\varepsilon^{2}}{k}
\end{aligned}
$$

where $G_{k}$ is production term of turbulence energy $k$ produced by average velocity gradient, $c_{1 \varepsilon}, c_{2 \varepsilon}$, and $c_{3 \varepsilon}$ are empirical constants, $\sigma_{k}$ and $\sigma_{s}$ are Prandtl numbers of turbulence kinetic energy $k$ and dissipation rate $\varepsilon$, and turbulence viscosity is defined as

$$
\mu_{t}=\rho C_{\mu} \frac{k^{2}}{\varepsilon}
$$

where $C_{\mu}$ is the empirical constant.

\subsection{Boundary Conditions and Numerical Model}

2.3.1. Inlet Boundary Conditions. Velocity inlet surface, where velocity and other scalars are defined, is chosen as the inlet boundary. Inlet velocity can be calculated by

$$
u_{\mathrm{in}}=\frac{Q}{\rho \pi\left(r_{1}^{2}-r_{2}^{2}\right)},
$$

where $Q$ is flow, and $r_{1}$ and $r_{2}$ are inlet cross section radii.

Inlet turbulence energy $k$ is calculated as

$$
k_{\text {in }}=0.005 u_{\text {in }}^{2} \text {. }
$$

Inlet dissipation rate $\varepsilon$ is calculated as

$$
\varepsilon_{\text {in }}=\frac{C_{\mu} k_{\text {in }}^{3 / 2}}{l_{\text {in }}},
$$

where $l_{\text {in }}$ is inlet mixing length, $D$ is inlet equivalent diameter, and $l_{\text {in }}=0.5 D$.

2.3.2. Outlet Boundary Conditions. The exit is set as outflow boundary which is mainly used where the exit flow is under full-developed state. The outlet velocity $u_{\text {out }}$, turbulence kinetic energy $k_{\text {out }}$, and dissipation rate $\varepsilon_{\text {out }}$ are described in the following equations:

$$
\begin{aligned}
\frac{\partial u_{i(\mathrm{out})}}{\partial n}=0 \quad(i=1,2,3, \ldots), & \\
\frac{\partial k_{\text {out }}}{\partial n} & =0, \\
\frac{\partial \varepsilon_{\text {out }}}{\partial n} & =0,
\end{aligned}
$$

where $n$ is the unit vector orthogonal to exit boundary.

2.3.3. Wall Boundary Conditions. No-slipping wall boundary conditions are assumed on the wall. The impeller boundary, front and back end plates are set as rotating wall, and other walls are stationary. Because the Reynolds number near the walls is small and standard $k-\varepsilon$ model is not appropriate to turbulent boundary layer region, logarithmic wall function is used.

2.4. Numerical Method. Multiple reference frame (MRF) is used in FLUENT and unsteady problem can be transferred into steady problem. Steady calculation is done in stator region, while centrifugal force and Coriolis force are calculated in rotor region in inertial frame and inner grids keep stationary during calculation. Flow parameters are switched between the interfaces of impellers and guide vanes in order to keep continuity of interfaces.

SIMPLE algorithm is used to couple pressure with velocity, and segregated solver and standard discrete scheme are chosen. First order upwind scheme is used to solve momentum conservation equation, turbulence energy equation, and dissipation rate equation. Underrelaxation factor controls the convergence speed and is properly updated based on actual convergence condition. 
TABLE 1: Design condition and fluid physical properties.

\begin{tabular}{lcccc}
\hline $\begin{array}{l}\text { Flow } \\
\left(\mathrm{m}^{3} / \mathrm{h}\right)\end{array}$ & $\begin{array}{c}\text { Rotational } \\
\text { speed } \\
(\mathrm{r} / \mathrm{min})\end{array}$ & $\begin{array}{c}\text { Atmospheric } \\
\text { pressure } \\
(\mathrm{Pa})\end{array}$ & $\begin{array}{c}\text { Medium } \\
\text { density } \\
\left(\mathrm{kg} / \mathrm{m}^{3}\right)\end{array}$ & $\begin{array}{c}\text { Dynamic } \\
\text { viscosity } \\
(\mathrm{Pa} \cdot \mathrm{s})\end{array}$ \\
\hline 20 & 2850 & 101325 & 998.2 & $1.003 \times 10^{-3}$
\end{tabular}

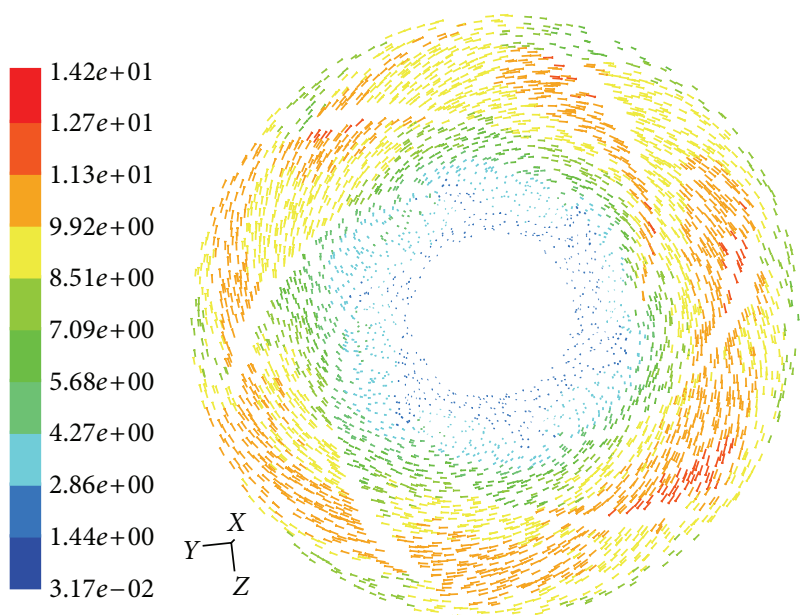

FIGURE 5: Relative velocity vector of impellers.

2.5. Design Condition of Pump and Fluid Properties. The design condition of pump and fluid physical properties are shown in Table 1.

\section{Numerical Results}

3.1. Velocity Distribution. Figure 5 shows the relative velocity vector of $x=0$ section in the middle of front end plate and back end plate of impellers under design condition. It can be seen from the figure that the flow is uniform in most fluid region of impellers without eddy, backflow, and separation flow. Jet-wake phenomenon happens only along individual blades. The flow velocity increases gradually from the inlet of impeller to exit, being slowest at the inlet and fastest at the exit. Because of diffusion function of guide blades, kinetic energy of high-speed fluid is transferred into pressure energy, and velocity becomes lower when fluid goes into the guide blade. Meanwhile a part of the energy is lost when the highspeed fluid flowing out of impellers collides into the pump case. The figure also shows that the relative velocity of suction surface is lower than that of pressure surface on the same radius surface. The pressure difference which is produced on the two sides of impellers due to the asymmetry creates the moment of resistance which is overcome by the prime mover to work on the spindle.

Figure 6 shows the absolute velocity of guide vanes under design condition. From the figure we can see that the velocity is fastest at the inlet of guide vane and slowest at the exit. The guide vanes transfer the kinetic energy of fluid into pressure energy. As a result, the velocity decreases gradually along the

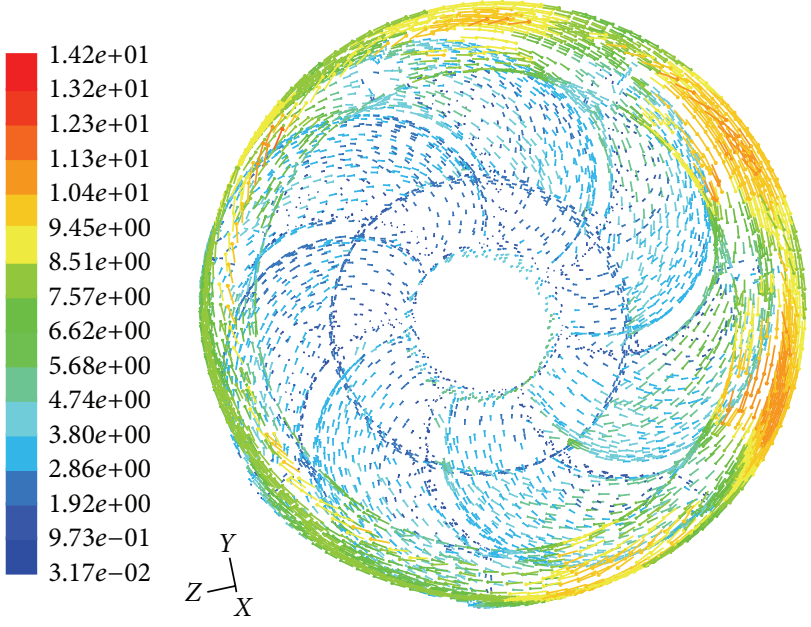

FIGURE 6: Absolute velocity vector of guide vanes.

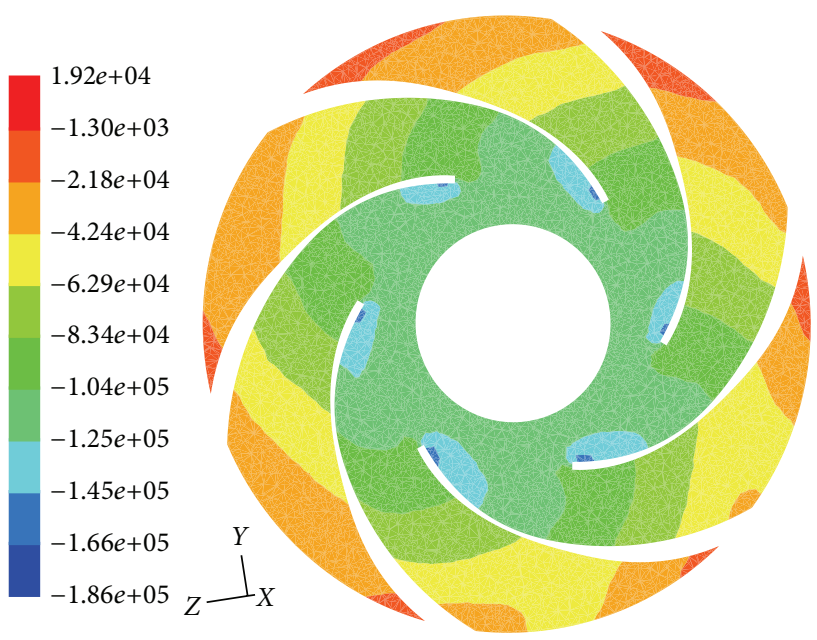

FIGURE 7: Static pressure distribution on impellers.

direction of the flow in the guide vane and secondary flow appears at blade end and exit.

3.2. Static Pressure Distribution. Figure 7 shows the static pressure distribution on the centrifugal pump impellers of $x=0$ section. It shows that the static pressure increases gradually and is ladder-like uniform distribution. The minimum pressure area appears at the suction surface of impeller inlet. The fluid can get the kinetic energy driven by impellers when it enters into the impeller flow channel vertically, but because the velocity direction changes quickly and some energy gets lost when the fluid collides into the impeller front end, cavitations could happen in these low-pressure areas. Figure 8 shows the static pressure distribution on suction surface and pressure surface of impellers, respectively. The pressure which shows ladder-like distribution gradually increases along the 


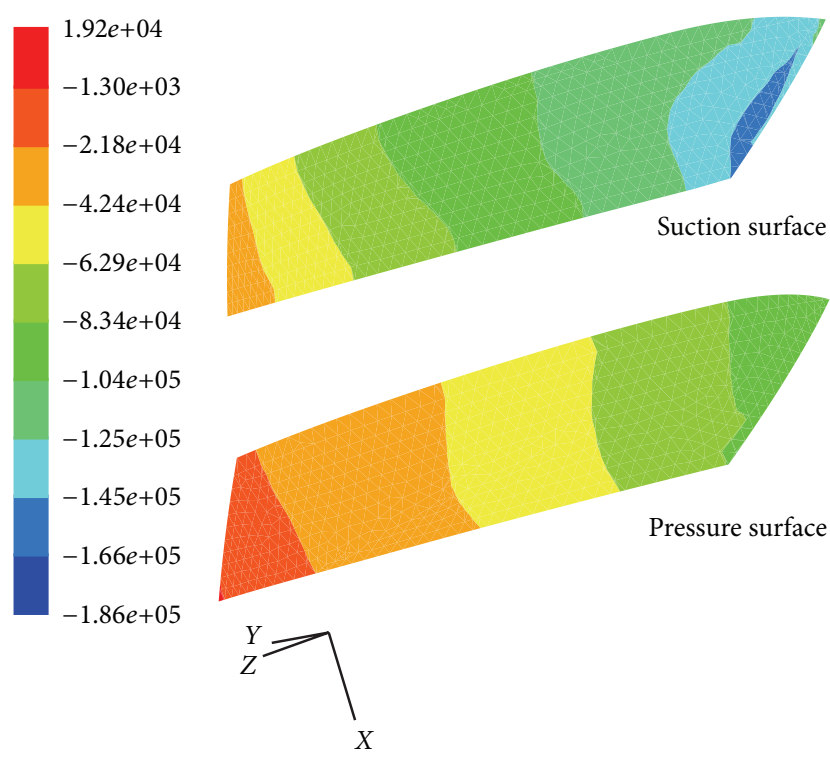

Figure 8: Static pressure distribution on suction surface and pressure surface of impellers.
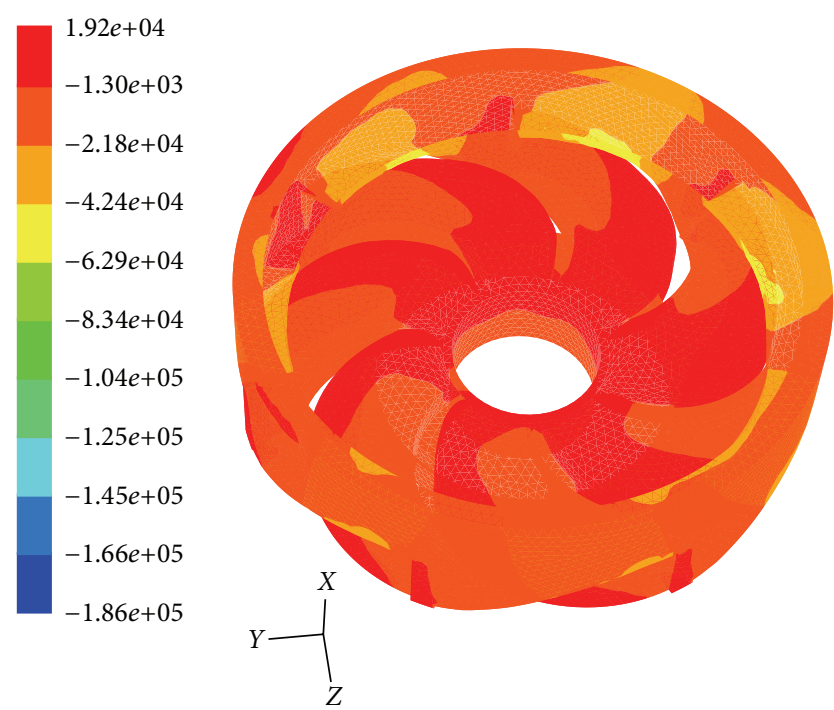

FIGURE 9: Static pressure distribution on guide vanes.

flow direction on both pressure and suction surfaces. The pressure on pressure surface is higher than that of suction surface and the pressure difference causes the moment of resistance on rotating axis. At the inlet of suction surface the pressure is lowest and cavitations may happen here.

Figure 9 shows the static pressure distribution on guide vanes of centrifugal pump under the design condition. It shows that the pressure increases gradually along the flow direction and reaches the maximum value at the exit of guide vanes. The function of guide vanes is to collect the high-speed fluid and then transfers kinetic energy of the fluid into pressure energy. Because of the crash between high-speed fluid from impellers and pump case, local low pressure appears in the interface of impellers and guidevanes,

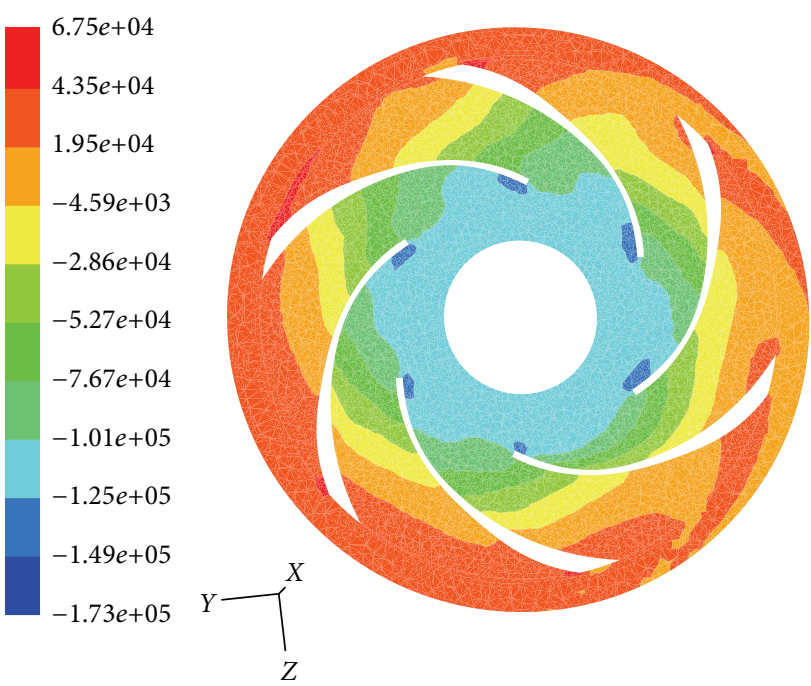

FIgURE 10: Total pressure distribution of centrifugal pump.

but it disappears when the fluid enters into the guide vanes. Figure 10 shows the total pressure distribution of the centrifugal pump on $x=0$ section. It shows that the total pressure increases gradually which is ladder-like uniform distribution when fluid flows from the impeller inlet exit, and then enters into the guide blade. It displays different pressure distribution at the impeller export and the entrance of guide vanes because the blade number of the guide vane is 7 and that of the impellers is 6. Due to the different blade number, the relative location of different flow channels displays asymmetric distribution when the impellers rotate.

\section{Performance Prediction Based on Numerical Simulation}

In order to predict the hydraulic performances of centrifugal pump, the external characteristics including flow, shaft power, lift, and efficiency are calculated.

The flow of inlet surface $Q$ in the centrifugal pump is defined as follows:

$$
Q=\int_{A}(\rho \vec{v} \cdot \widehat{n}) d A
$$

where $A$ is the area of the inlet or exit of the centrifugal pump, $\vec{v}$ is the velocity vector of the calculation element, $\rho$ is fluid density, and $\hat{n}$ is direction vector on the inlet surface or the exit surface.

The total pressure on the inlet and exit surfaces is respectively defined by the pattern of the mass average value as follows:

$$
P_{i}=\frac{\int_{A}\left(\rho p_{t}|\vec{v} \cdot \hat{n}|\right) d \mathrm{~A}}{\int_{A}(\rho|\vec{v} \cdot \hat{n}|) d A},
$$

where $p_{t}$ is the total pressure of the calculation element. 
The lift of centrifugal pump is shown as follows:

$$
H=\frac{p_{\text {out }}-p_{\text {in }}}{\rho g}+\frac{v_{\text {out }}^{2}-v_{\text {in }}^{2}}{2 g}+\Delta Z,
$$

where $P_{\text {in }}$ and $P_{\text {out }}$ are, respectively, the total pressure of the inlet and exit. $\Delta Z$ is the vertical distance between the inlet and exit. $v_{\text {in }}$ and $v_{\text {out }}$ are, respectively, the speed of the inlet and exit. $g$ is gravity acceleration.

The shaft power is calculated as follows:

$$
\begin{aligned}
& P=M w, \\
& w=\frac{2 \pi n}{60},
\end{aligned}
$$

where $M$ is the total moment of pressure surface, suction surface, and front and back end plates around $z$ axis, $n$ is the rotated speed, and $w$ is the angular velocity.

The centrifugal pump efficiency is shown as follows:

$$
\eta=\frac{\rho g Q H}{M w} .
$$

In addition to the design condition, the paper simulates different flow conditions of $0.5 Q, 0.7 Q, 0.8 Q, 0.9 Q, 1.1 Q, 1.2 Q$, $1.3 Q$, and $1.5 Q$ to attain the lift, shaft power, and efficiency, as shown in Table 2.

\section{Experiment Verification}

In order to verify the reliability of the results of numerical simulation, experiments are designed to test the flow, lift, shaft power, and efficiency of the 20BZ4 centrifugal pump. Figures 11, 12, and 13 show, respectively, the experimental characteristic curves of flow and lift, flow and shaft power, and flow and efficiency. The figures show that there are certain differences between the experimental results and numerical results. When the pump physical model is built, the gap region between front and back plates and case is ignored, so the rotation of pump is accompanied by a volume loss. Furthermore mechanical loss such as bearing friction loss and disc loss are also ignored.

Figure 11 shows the relation curve between the flow and lift. The simulation curve has no hump, and it demonstrates that the centrifugal pump has good performances. The trends of experimental curve and simulation curve are consistent. But in addition to the design condition, the experimental data and calculated data in the high flow and low flow have larger difference. MRF is a kind of assumed steady calculation flow model relative to the design condition, so the unsteady factors of flow field are fewer near the design condition and the calculated data and experimental data are consistent. However under off-design conditions, there are many unsteady factors such as the crash between the fluid and pump shell and blade boundary layer separation, which results in difference between calculated data and experimental data.

Figure 12 shows the relation curve between the flow and shaft power. Because the calculated moment is lower than

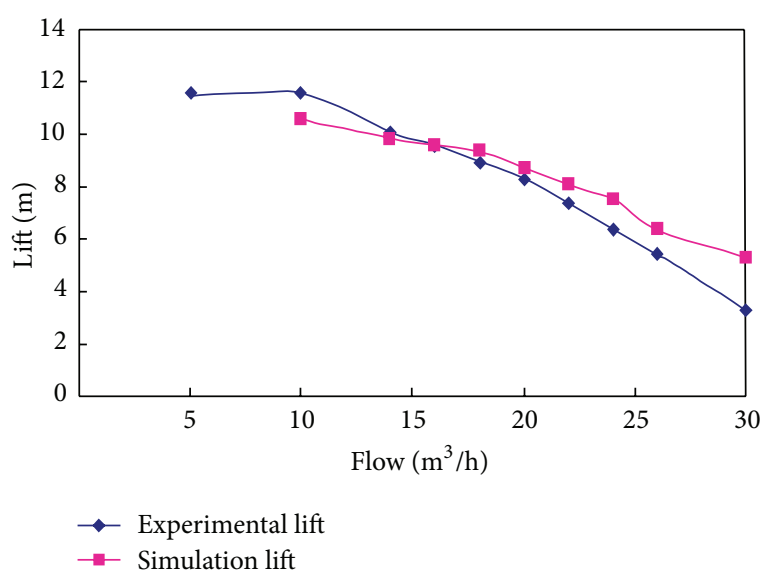

Figure 11: Performance curves of flow-lift.

the experimental moment, so the shaft power of numerical simulation is lower than that of experiment. However under high flow conditions, the shaft power of numerical simulation is higher than that of experiment, which is because the relative ideal numerical model is used and the distribution of the unsteady factors in the flow is not taken into account.

Figure 13 shows the relation curve between the flow and efficiency. It demonstrates that the curve first goes up and then down and it becomes relatively flat near the region of design condition. The flow region of high efficiency is wide which demonstrates that the performance is stable around the design condition. When the pump physical model is built, the gap region between front and back plates and case is ignored, so the rotation of pump is accompanied by a volume loss. Furthermore mechanical loss such as bearing friction loss and disc loss are also ignored. The actual losses cause the efficiency of numerical simulation to be higher than that of experiment, which can be seen from the figure.

\section{Conclusions}

(1) Complicated three-dimensional flow model is built including inlet region, impeller flow region, guide-vane flow region, and exit region to simulate flow in 20BZ4 multistage centrifugal pump. The method of multireference frame (MRF) is used to model rotating blades and stationary blades by FLUENT.

(2) The simulation results show that the flow in impellers is mostly uniform, no eddy, backflow, and separation flow. The Jet-wake along some blades influences the efficiency. There is secondary flow at blade end and exit of guide vanes. The pressure on pressure surface is higher than that of suction surface and the pressure difference causes the moment of resistance on rotating axis. At the inlet of suction surface the pressure is lowest and cavitations may happen there.

(3) Besides design condition, six off-design conditions are set to predict the external characteristics of hydraulic performances. The comparison between experimental data and simulation data shows that the experimental curve agrees well with the simulation curve under design condition, but 
TABLE 2: Performance data under off-design conditions of simulation.

\begin{tabular}{lccccccccc}
\hline Flow $\left(\mathrm{m}^{3} / \mathrm{h}\right)$ & $0.5 Q$ & $0.7 Q$ & $0.8 Q$ & $0.9 Q$ & $Q$ & $1.1 Q$ & $1.2 Q$ & $1.3 Q$ & $1.5 Q$ \\
\hline Lift $(\mathrm{m})$ & 10.57 & 9.89 & 9.57 & 9.34 & 8.73 & 8.05 & 7.48 & 6.38 & 5.29 \\
Shaft power $(\mathrm{w})$ & 546.3 & 617.9 & 634.7 & 666.5 & 686.4 & 711.7 & 763.3 & 760.7 & 856 \\
Efficiency $(\%)$ & 52.7 & 61.2 & 65.9 & 68.7 & 69.3 & 67.7 & 64 & 59.4 & 50.5 \\
\hline
\end{tabular}

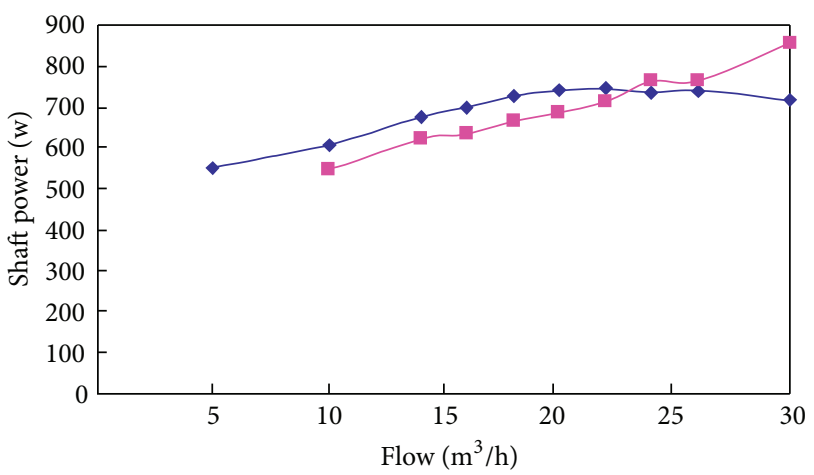

$\rightarrow$ Experimental data

$\rightarrow$ Simulation data

FIgURE 12: Performance curves of flow-shaft power.

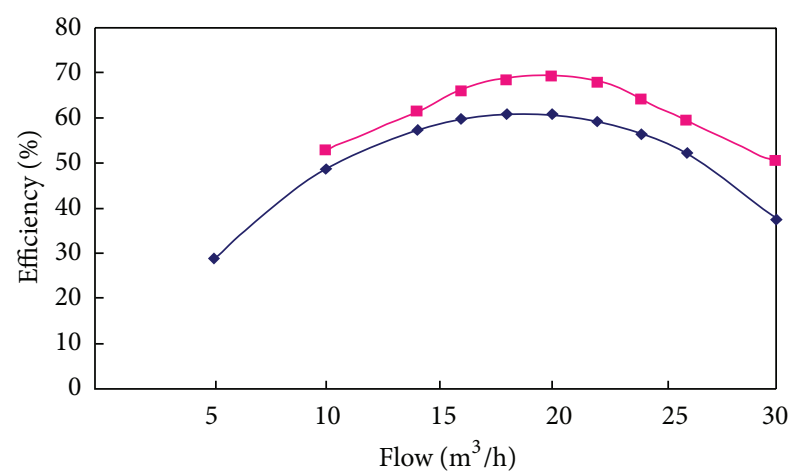

$\rightarrow$ Experimental data

$\rightarrow$ Simulation data

FIgURE 13: Performance curves of flow-efficiency.

under off-design conditions the unsteady factors of flow field influence the precision. The actual losses cause the efficiency of numerical simulation to be higher than that of experiment.

\section{References}

[1] J. Shi, "The energy conservation improvement and prospect of the centrifugal pump," General Machinery, vol. 9, pp. 24-28, 2012.

[2] H. Si and S. Dike, "Numerical simulation of the threedimensional flow field in a multistage centrifugal pump and its performance prediction," Mechanical Science and Technology, vol. 29, no. 6, pp. 706-708, 2010.

[3] Z. Li, D. Wu, L. Wang, and B. Huang, "Numerical simulation on internal flow of centrifugal pump during transient operation,"
Journal of Engineering Thermophysics, vol. 30, no. 5, pp. 781-783, 2009.

[4] Y. Liu and G. Wang, "Computer-aided analysis on inner flow in stamping and welding multistage centrifugal pump's impellers," Chinese Journal of Mechanical Engineering, vol. 43, no. 8, pp. 207-211, 2007.

[5] R. Barrio, J. Fernndez, E. Blanco, and J. Parrondo, "Estimation of radial load in centrifugal pumps using computational fluid dynamics," European Journal of Mechanics B, vol. 30, no. 3, pp. 316-324, 2011.

[6] B. Jafarzadeh, A. Hajari, M. M. Alishahi, and M. H. Akbari, “The flow simulation of a low-specific-speed high-speed centrifugal pump," Applied Mathematical Modelling, vol. 35, no. 1, pp. 242249, 2011.

[7] M. Asuaje, F. Bakir, S. Kouidri, F. Kenyery, and R. Rey, "Numerical modelization of the flow in centrifugal pump: volute influence in velocity and pressure fields," International Journal of Rotating Machinery, vol. 2005, no. 3, pp. 244-255, 2005.

[8] B. Cui, Z. Zhu, J. Zhang, and Y. Chen, "The flow simulation and ex perimental study of low-specific-speed high-speed complex centrifugal impellers," Chinese Journal of Chemical Engineering, vol. 14, no. 4, pp. 435-441, 2006.

[9] J. S. Anagnostopoulos, "Numerical calculation of the flow in a centrifugal pump impeller using Cartesian grid," in Proceedings of the 2nd WSEAS International Conference on Applied and Theoretical Mechanics, pp. 20-22, Venice, Italy, 2006. 


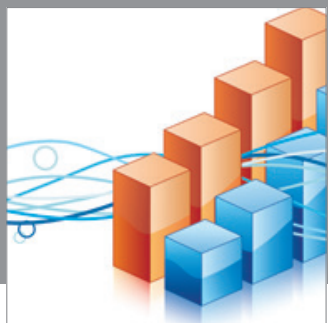

Advances in

Operations Research

mansans

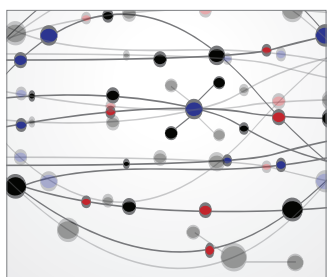

The Scientific World Journal
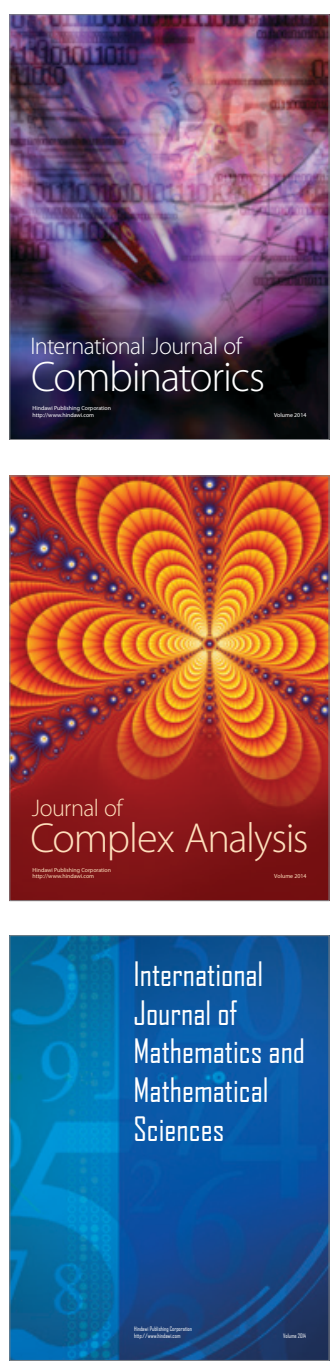
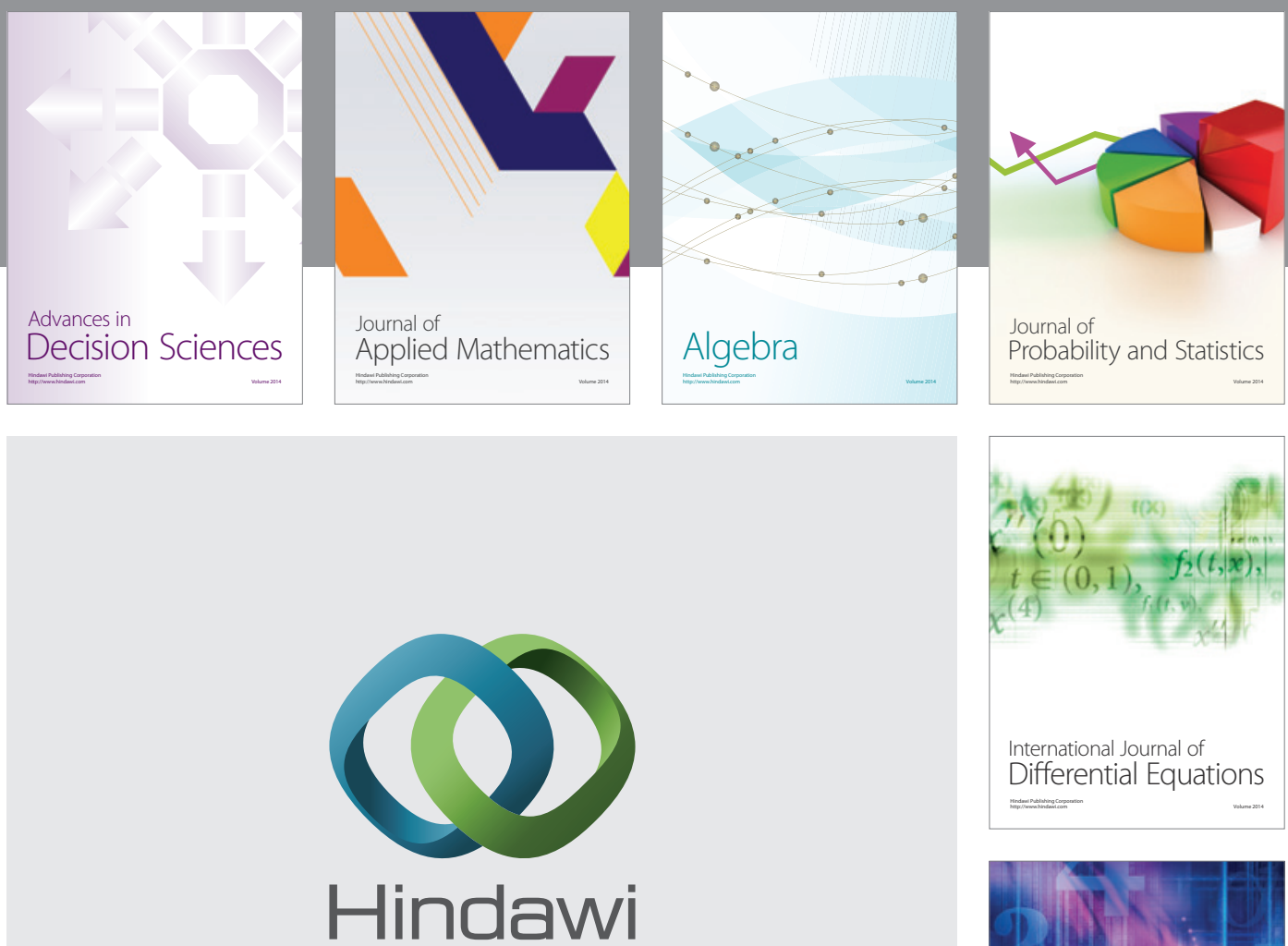

Submit your manuscripts at http://www.hindawi.com
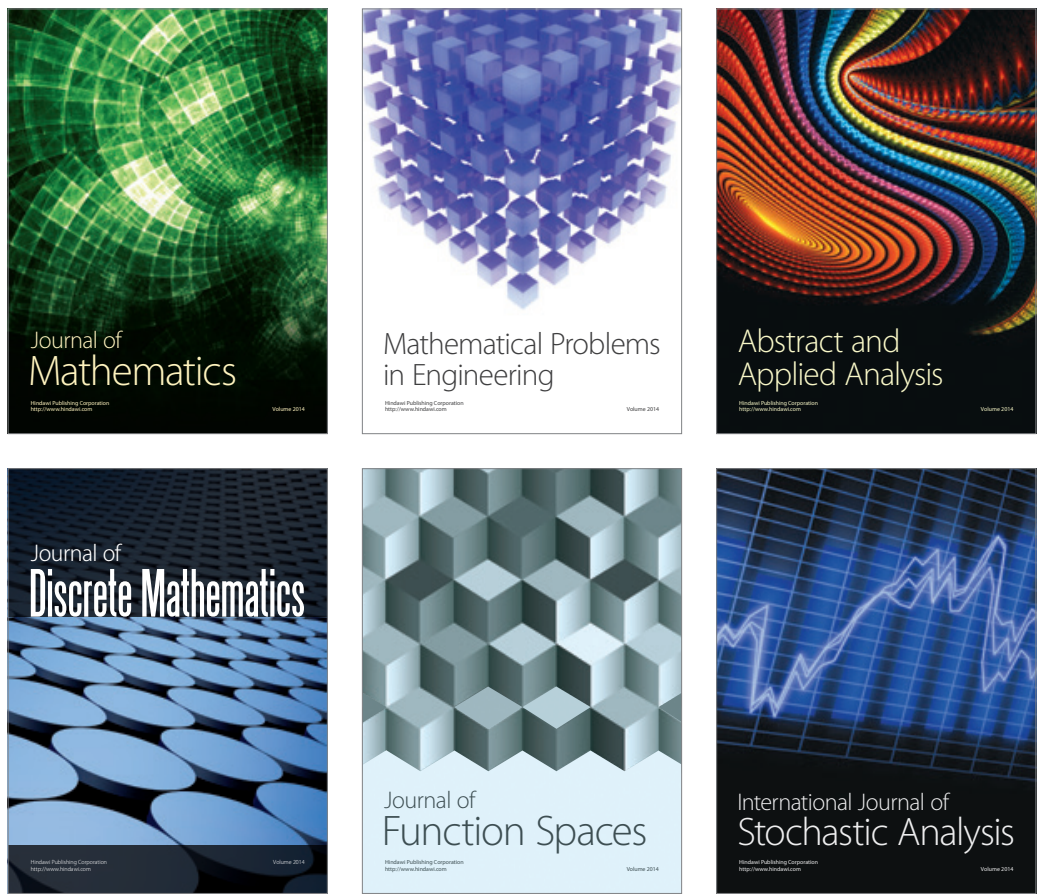

Journal of

Function Spaces

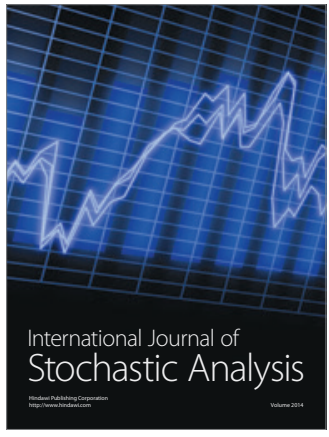

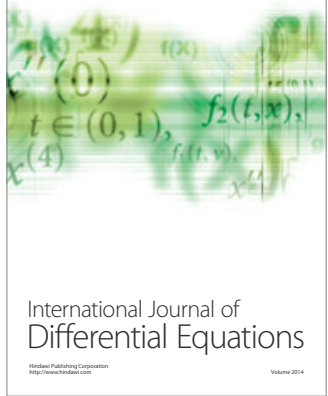
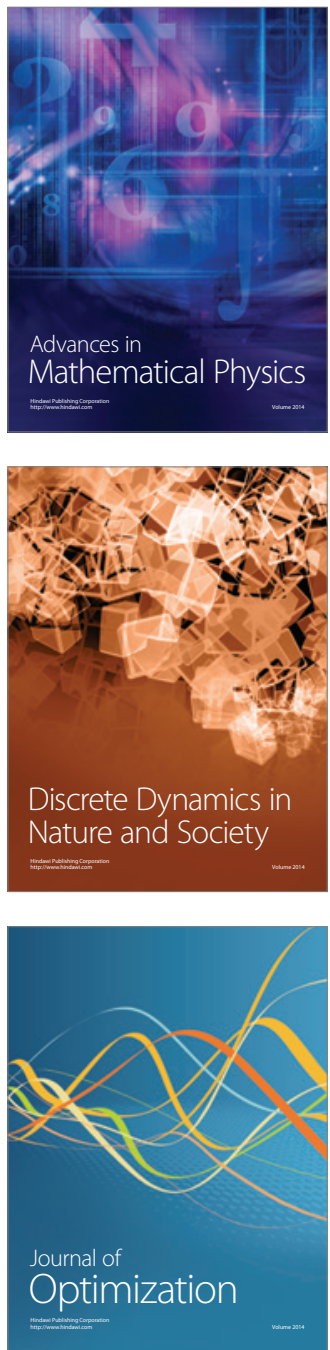